\title{
Statistical Examination of the Aerosols Loading over Mubi-Nigeria: the Satellite Oobservation Analysis
}

\author{
Emetere Moses Eterigho ${ }^{A}$ \\ Received: January 8, 2015 | Revised: April 7, 2016 | Accepted: June 1, 2016 \\ DOI: 10.18421/GP20.02-02
}

\begin{abstract}
The problem of underestimating or overestimating the aerosols loading over Mubi is inevitable because of the absence of ground stations over the region. Aerosols pollution is a global challenge to life forms as it affects human health, agricultural produce, thermal comfort and weather. The modulation between high and low thermal comforts over Mubi is quite disturbing. The aim of the research is to seek a more reliable approach to estimate the aerosols loading and retention over Mubi. Thirteen years aerosol optical depth (AOD) data was obtained from the Multi-angle imaging spectroradiometer (MISR). Mubi is located on latitude $10.270 \mathrm{~N}$ and longitude 13.270 E. Statistical tools, as well as analytically derived model for aerosols loading were used to obtain the aerosols retention and loading over the area. It was discovered that the highest aerosols retention over Mubi is $12.7 \%$. The atmospheric constants and tuning constants over Mubi were documented as 0.67 and 0.71 respectively. Due to the volume of aerosols over Mubi, it is necessary to change the International Telecommunication Union (ITU) model which relates to signal budgeting.
\end{abstract}

Keywords: aerosols retention, Mubi, atmospheric constant, statistical tool, analytical dispersion model

\section{Introduction}

Atmospheric aerosols are systems of solid or liquid particles suspended in air or other gaseous environment. They have definite lifetimes and vary in size, thus there is a wide range of them, from flame synthesized nanoparticles and nanomaterials (Stahlmecke, et al., 2009). This basic properties makes it a source of concern as regards human health, thermal comfort, agricultural produce (because it modifies both rain pattern heat flux and cloud formation) and communication. The number of particles, mass distribution, dusty flows, the deposition rate and the mean size of the particles have been estimated in several countries, especially in Ghana (Sunnu, et al., 2008) Mali (McTainsh, et al., 1997), and Nigeria (Anuforom, 2007). Nigeria is one of the countries in west Africa most exposed to desert dust because of its proximity to the main emission source area and its location with regard to the dominant winds. Studies show that the dust quantity which varies from year to year is greater in the Northern parts of these countries and the dust particles become finer in size as they move further south (Rutherford, et al., 1999; Anuforom, 2007; Uduma, Jimoh, 2013).

Mubi has about 5.6 million inhabitants that spread across a large expanse of land. The major occupation of the populace is farming. Hence, it is expected that large biomass burning occurs over Mubi. The reliance on fossil fuel for farm machineries and automobile shows that Mubi could confront severe challenges of air quality management in the future. The current climate change is affecting the environment in diverse ways. Among the atmospheric aerosols, mineral dust produced from windblown soils and deserts is one of

\footnotetext{
A Department of Physics, Covenant University Canaan land, P.M.B 1023, Ota, Nigeria, 122333; e-mail: emetere@yahoo.com
} 
the largest contributors to the global aerosol loading and has strong impacts on human health (Emetere, et al., 2015). Harmathan dust is considered to be among the most harmful of all air pollutants due to the toxic effect of the dust constituents. Like any other part of West Africa, aerosols retention and loading over Mubi cannot be estimated because of the high influence of anthropogenic and natural pollution. Unfortunately, most regions over West Africa has no ground station to ascertain its aerosols retention or loading.

The immediate causes of anthropogenic and natural pollution include the deposition of pollutants to the surface of the earth as well as to bodies of water (Kommalapati, et al., 2009); initiation of acid rain which pollutes water bodies, damage buildings and kills soil microbes; causes respiratory challenges. Aerosol particles with an effective diameter smaller than $10 \mu \mathrm{m}$ can enter the bronchi, while the ones with an effective diameter smaller than $2.5 \mu \mathrm{m}$ can enter as far as the gas exchange region in the lungs (Kommalapati, et al., 2009), which can be hazardous to human health. Respiratory infections make up more than $20 \%$ of the causes of infant mortality and morbidity (Morris, et al., 2003; Bryce, et al., 2005). Side the respiratory challenges experienced, other ailments like cough, muscular aches and pains, painful watery eyes (Apollo), and unusual high body temperature occurs during the Harmattan periods in Mubi (SITREP, 2014). This effect has extended to the mortality of livestock in Mubi (Mubi, et al., 2011).

Therefore an in-depth study of the aerosols over Mubi is paramount to protect life forms against natural disasters that accompany aerosols loading. In the present study, a stastistical examination of the aerosols loading over Mubi-Nigeria was observed and an analytical dispersion model were adopted to monitor the aerosols loading, as well as the aerosols retention. These technique provides an accurate estimation of aerosols loading over a geographical region with the help of satellite observation.

\section{Validation of data source}

In the past, no aerosols ground observation was available; hence, the satellite observation was adopted. Fourteen years satellite observation was obtained from the Multi-angle Imaging SpectroRadiometer (MISR). The MISR operates at various directions i.e. nine different angles (70.50, 600, 45.60, 26.10, 00, 26.10, $45.60,600,20.50)$ and gathers data in four different spectral bands (blue, green, red, and near-infrared) of the solar spectrum. The blue band is at wavelength $443 \mathrm{~nm}$, the green band is at wavelength $555 \mathrm{~nm}$, the red band wavelength $670 \mathrm{~nm}$ and the infrared band is at wavelength $865 \mathrm{~nm}$. MISR acquire images at two dif- ferent levels of spatial resolution i.e. local and global mode. It gathers data at the local mode spatial resolution of 275 meter pixel size and $1.1 \mathrm{~km}$ at the global mode. Typically, the blue band is to analyze coastal and aerosol studies. The green band is to analyze Bathymetric mapping and estimating peak vegetation orbits (Wiki, 2016). The red band analysis the variable vegetation slopes and the infrared band analysis the biomass content and shorelines. MISR has three product levels. Product level 1 eliminates map errors due to instrument; product level 2 are used to calculate salient indexes; product level 3 combines regional maps from multiple orbits (Wiki, 2016).

\section{Location of Study}

Mubi is the second populous city in Northern Nigeria and it is located on latitude $10.27^{\circ} \mathrm{N}$ and longitude $13.27^{\circ} \mathrm{E}$ in the Sahelian geographic region of West Africa (Figure 1). Mubi is under the influence of the local steppe climate. Its metropolitan area is about $36,917 \mathrm{~km}^{2}$. Mubi has an average temperature and precipitation of $26.1^{\circ} \mathrm{C}$ and $752 \mathrm{~mm}$ respectively. The distance of Mubi to the Sahara is about $2826 \mathrm{~km}$.

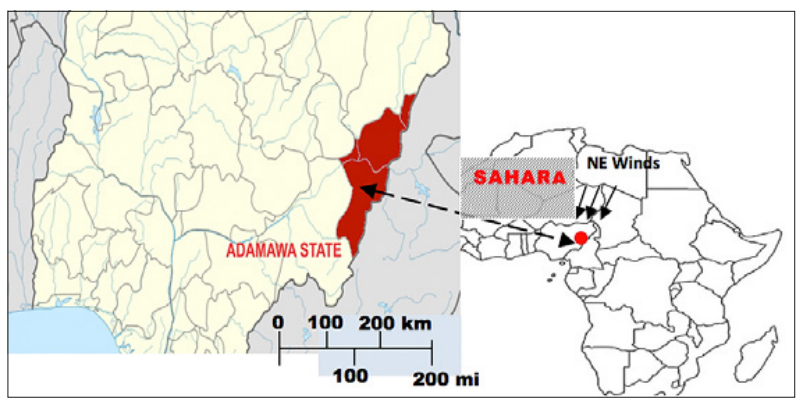

Figure 1. Map of Mubi and the Sahara influence

\section{Methodology}

The standard error (SE) of the mean is expressed mathematically as

$S E=\frac{\sigma}{\sqrt{n}}$

Here is the population standard deviation and is the population size.

Standard error measures the uncertainty in aerosol optical depth parameter and the deviations of the monthly mean from the thirteen-years mean. Standard deviation $(\sigma)$ measures the amount of visible dispersion from the monthly mean. Like the SE, a low magnitude standard deviation signifies that the monthly mean is closer to the thirteen-years mean also called expected value. Also, a high magnitude standard deviation signifies how far monthly mean is 
from the thirteen-years mean. Standard deviation is given as

$$
\sigma=\sqrt{\frac{1}{N} \sum_{j=1}^{N}\left(y_{i}-\bar{y}\right)^{2}}
$$

Here in the context of our research is the monthly-mean, is the mean value of the thirteen-year mean in a set of $\mathrm{N}$ values. The concept of variance is intrinsically connected with the effects of the difference between the monthly mean and the thirteen-years mean on the aerosol optical depth (AOD) performance in Mubi, Nigeria. The coefficient of variation is the measure of a normalized dispersion of probability distribution i.e. the thirteen years mean for each parameter used. In statistics, coefficient of variation is referred to as relative standard deviation and expressed in percentage. Coefficient of variation is not used for few meteorological parameters because of the inconsistency of its interval scale. For example, coefficient of variation is appropriate for the Kelvin scale and inappropriate for the Celsius scale because its data has interval scale i.e. can accommodate both negative and positive values. Therefore, we adopted the coefficient of variation because the scale used has interval scale and appropriate for comparison between data sets of widely different yearly or monthly means. Coefficient of variation can be represented mathematically as

$$
C V=\frac{\sigma}{\mu}
$$

Here is the standard deviation and is the monthly mean. Skewness, denoted as ' $\mathrm{X}$ ' is a measure of the asymmetry of the probability distribution of the monthly mean about its thirteen-year mean. For a normal distribution, the skewness is equivalent to zero. The skewness value can be positive, negative, or undefined. When the skew is negative, it indicates that the mass of the distribution is concentrated on the right of the plotted graph i.e. left-skewed. When the skew is positive, the mass of the distribution is concentrated on the left of the plotted graph i.e. rightskewed (Weisstein, 2005). The Skew of a distribution can be written mathematically as

$$
X=\frac{(\mu-v)}{E(|X-v|)}
$$

Here is the median, $\mathrm{E}$ is the expectation error, $\mathrm{X}$ is the Skew of a distribution.

Kurtosis $(\beta)$ is any measure of the flattening or "peakedness" of the probability distribution of the monthly mean for each month of the year (Weisstein, 2004). Like skewness, kurtosis is a descriptor of the shape of a probability distribution which can be interpreted as $\beta>3$ (Leptokurtic distribution- high probability for extreme values), $\beta<3$ (Platykurtic distribution- probability for extreme values is less than for a normal distribution) and $\beta=3$ ( Mesokurtic distribution - normal distribution) (Weisstein, 2004). Kurtosis mathematically written as

$\beta=\frac{\mu^{4}}{\sigma^{4}}$

All parameters retain its usual meaning. The simulation was carried-out using Surfer analytical tool.

The raw MISR dataset from 'http://giovanni.sci. gsfc.nasa.gov/giovanni' was processed using the Excel package. The mean for each months were calculated for each year. We tested the accuracy of the data by applying the aerosol dispersion model that was propounded by Emetere et al. (2015a). An extension of the dispersion model used is given as

$$
\begin{aligned}
& \psi(\lambda)=a_{1}^{2} \cos \left(\frac{\mathrm{n}_{1} \pi \tau(\mathrm{l})}{2} x+\alpha\right) \cos \left(\frac{\mathrm{n}_{1} \pi \tau(\lambda)}{2} y+\beta\right)+ \\
& +a_{2}^{2} \cos \left(\frac{\mathrm{n}_{\mathrm{n}} \pi \tau(\lambda)}{2} x+\alpha\right) \cos \left(\frac{\mathrm{n}_{\mathrm{n}} \pi \tau(\lambda)}{2} y+\beta\right)
\end{aligned}
$$

Here and are the phase differences, $\mathrm{k}$ is the diffusivity, is the AOD, is the concentration of contaminant, is the wavelength, $\mathrm{a}$ and $\mathrm{n}$ are atmospheric and tuning constants respectively.

The percentage of retention can be determined from the coefficient of variance for each year. This was done by considering the previous and current years which are denoted as and respectively. Hence we propound that the aerosols retention between two years as:

$A=\left|\frac{G_{p}-G_{r}}{G_{p}}\right|^{2} \cdot 100 \%$

The aerosols retention can be calculated from Figures 3-4 to obtain Tables 1-2. Any statistical tool could be used to obtain the atmospheric aerosols retention. In this paper, the Matlab and the Excel package were used to obtain the results shown in the succeeding section.

\section{Results and discussion}

Mubi monthly AOD trend agreed perfectly with the proposed model (Figures 2, 5-8). The aerosol optical depth (AOD) pattern over Mubi is a gamma distribution with the average maximum in April and 
March. From Figure 2, it can be inferred that the type of aerosols in Mubi is majorly dust particulates from the northeast wind. This is because dust content in the atmosphere can be reduced by a process known as 'rain-wash'. Rain-wash is a self cleansing mechanism used by the atmosphere to purge itself. Therefore if there is a drastic drop in aerosol optical depth, there is the possibility that the particulates are majorly dust. The AOD retrieval technique by MISR is perfect over Mubi. Accuweather (2015) showed that Mubi has a more stable weather compared to other parts of the northern Nigeria. Figure 1 is further clarified using Figures 3 and 4.

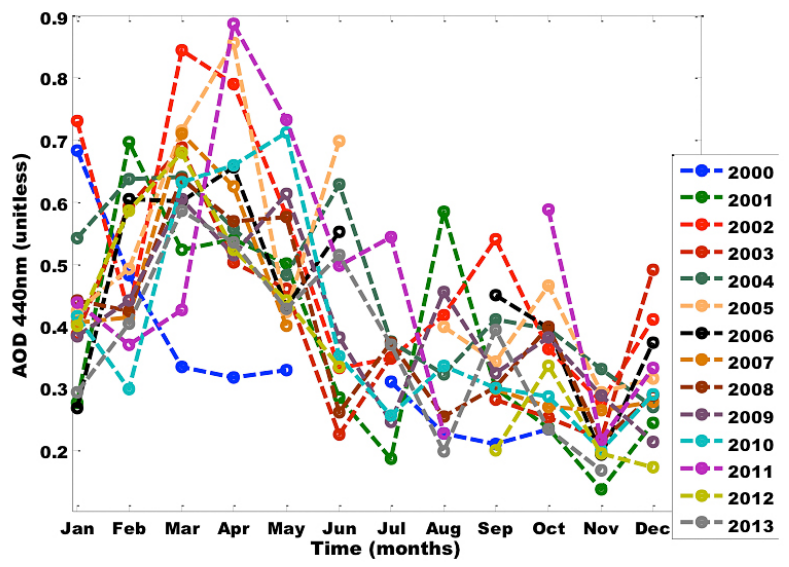

Figure 2. AOD pattern for Mubi 2000-2013
The highest aerosol optical depth of 0.86 occurred in 2002, 2005 and 2011. The lowest aerosol optical depth of 0.14 occurred in 2001 and 2013. The average AOD over Mubi is given as 0.44 . The aerosol loading cannot be known from Figure 1 and 3-4. Equation (6) was used alongside the Matlab curve fitting tool to obtain the aerosol loading obtained in Figures 5-8. The properties of the 'goodness of fit' for all the curves in Figures 5-8 have sum of squares due to error (SSE) of 0.006216 . The R-square is given as 0.9468. R-square measures how successful curve fits in explaining the variation of AOD data. From the data, it is shown that the proposed model is able to explain $94.68 \%$ of the total variation in the MISR data. This typifies that the proposed model is somewhat accurate for nowcast or forecast purposes

From Figures 2, 5-8, the atmospheric constants, phase differences and tuning constants can be inferred from the Matlab curve fit tool and equation (6) as shown in Table 1. The bar analysis og AOD over Mubi is given in Figures 3 and 4 .

The statistical analysis of the proposed model in Mubi was within 95\% confidence bounds (Figures 5-8). Table 1 shows that when atmospheric constant 0.6085 is used in the flash card of the measuring instrument, the corresponding tuning constants should be 0.07197 . Also, when atmospheric constant 0.6326 is used in the flash card of the measuring instrument, the corre-

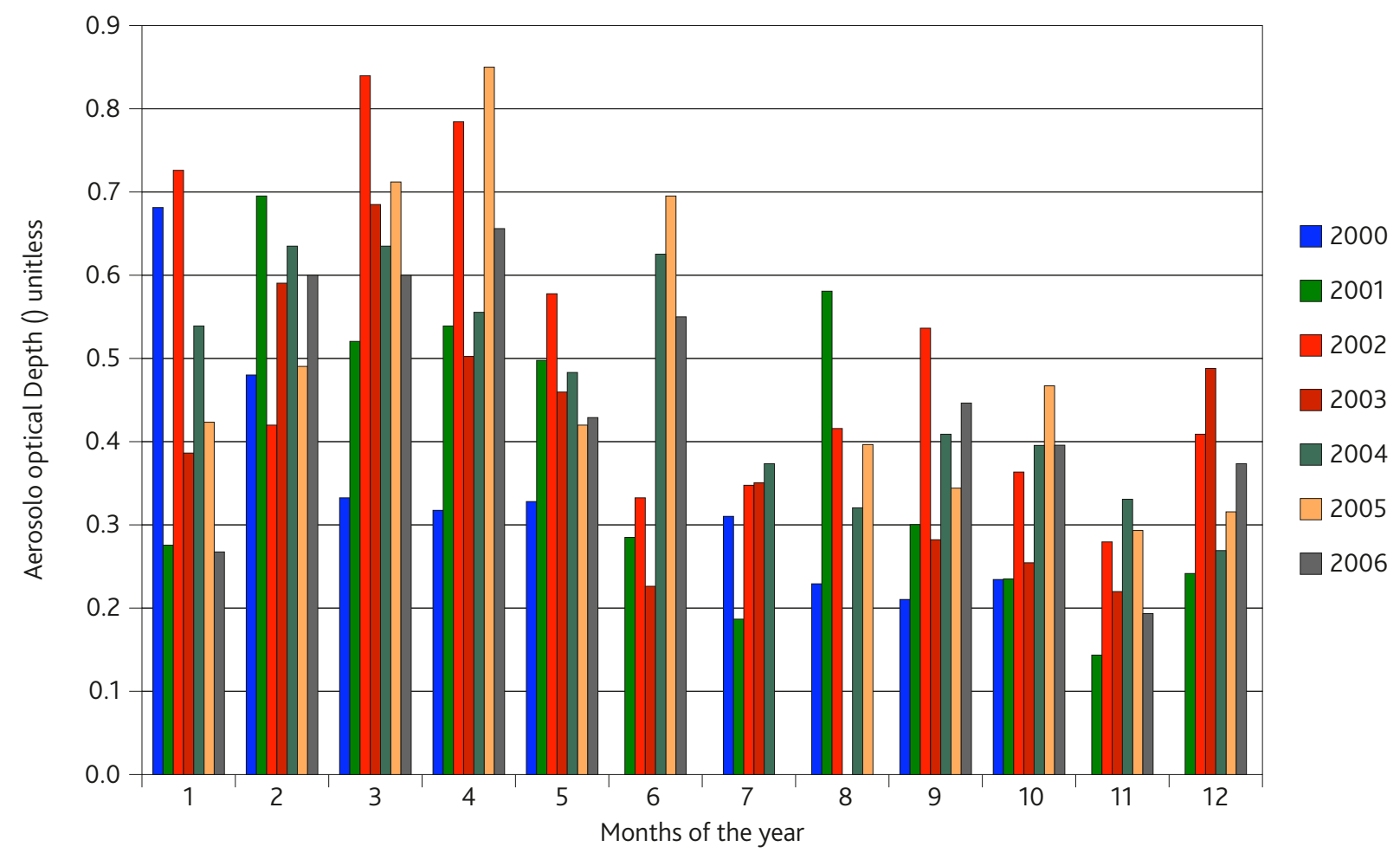

Figure 3. MISR aerosol optical depth for the 2000-2006 


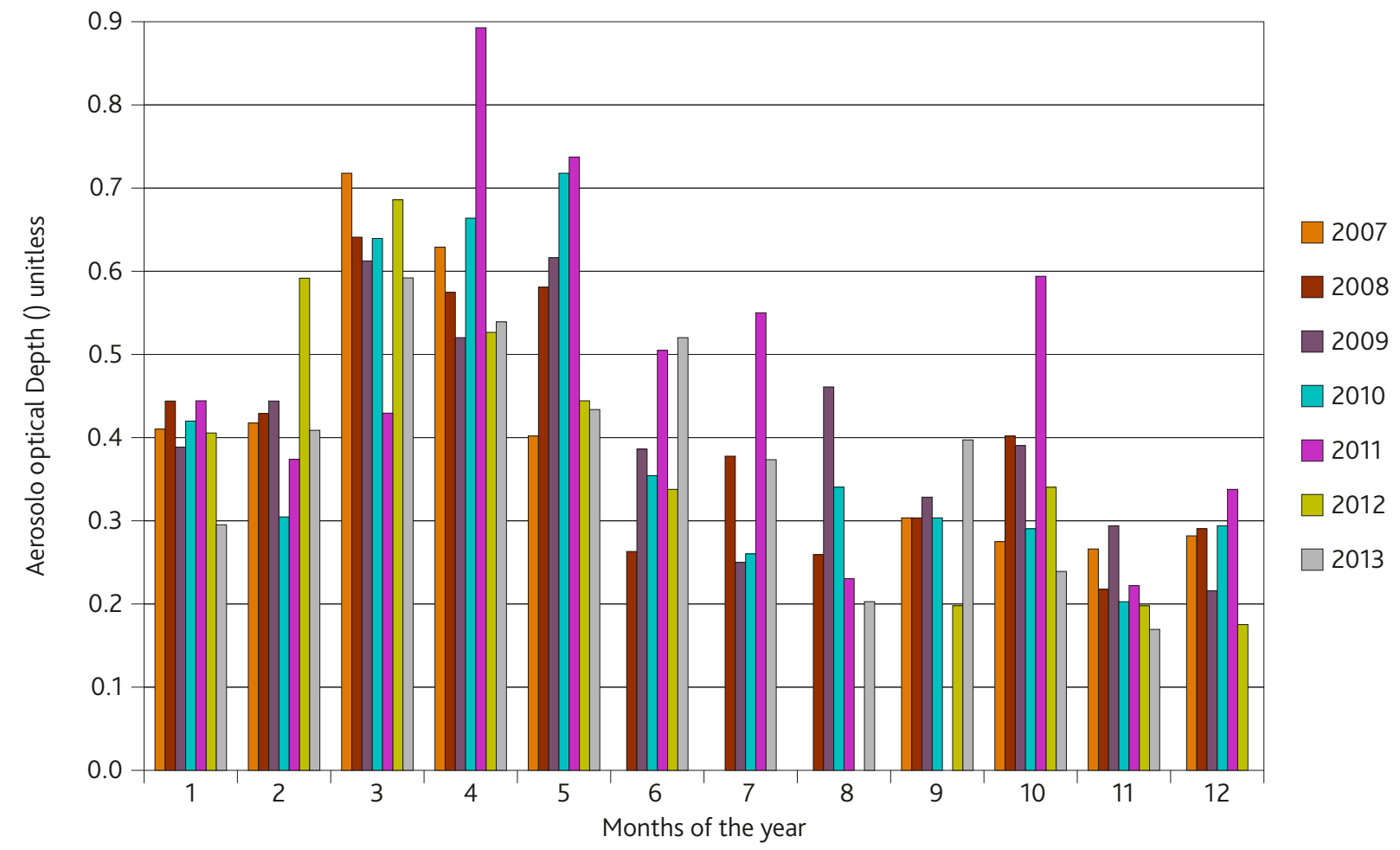

Figure 4. MISR aerosol optical depth for the 2007-2013

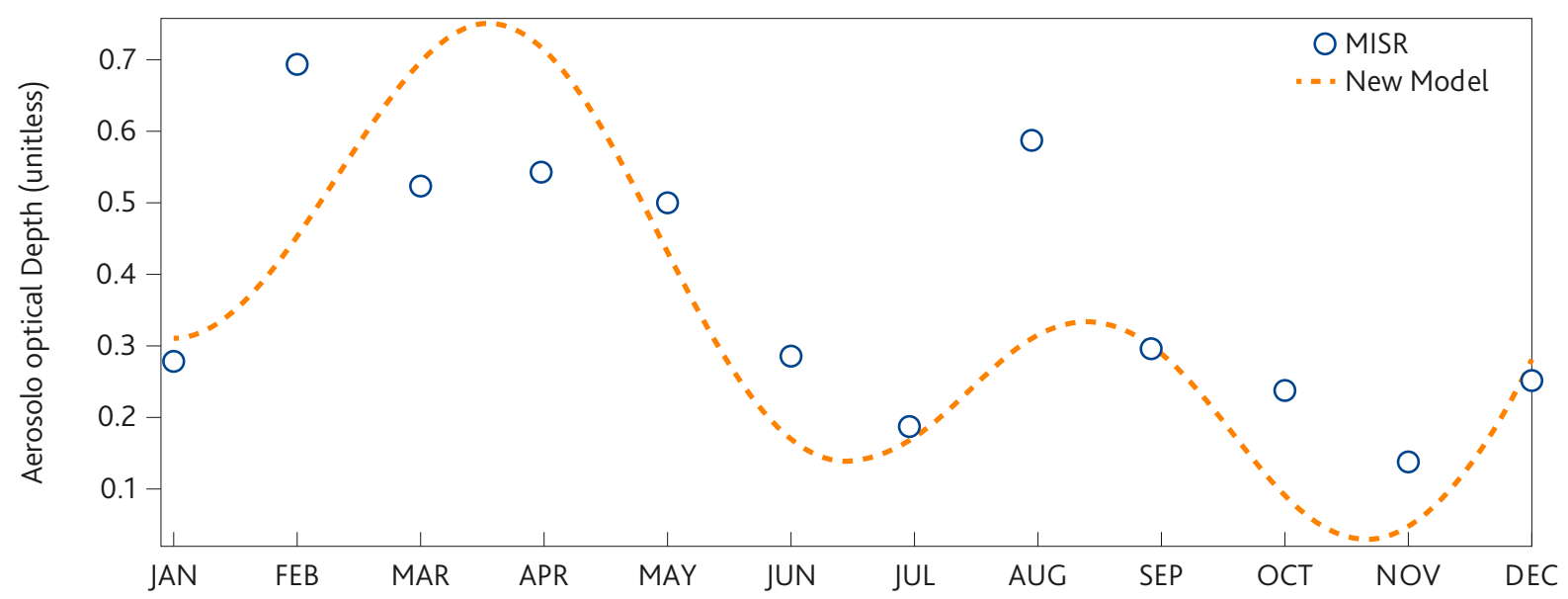

Figure 5. AOD for new model and MISR for the year 2001

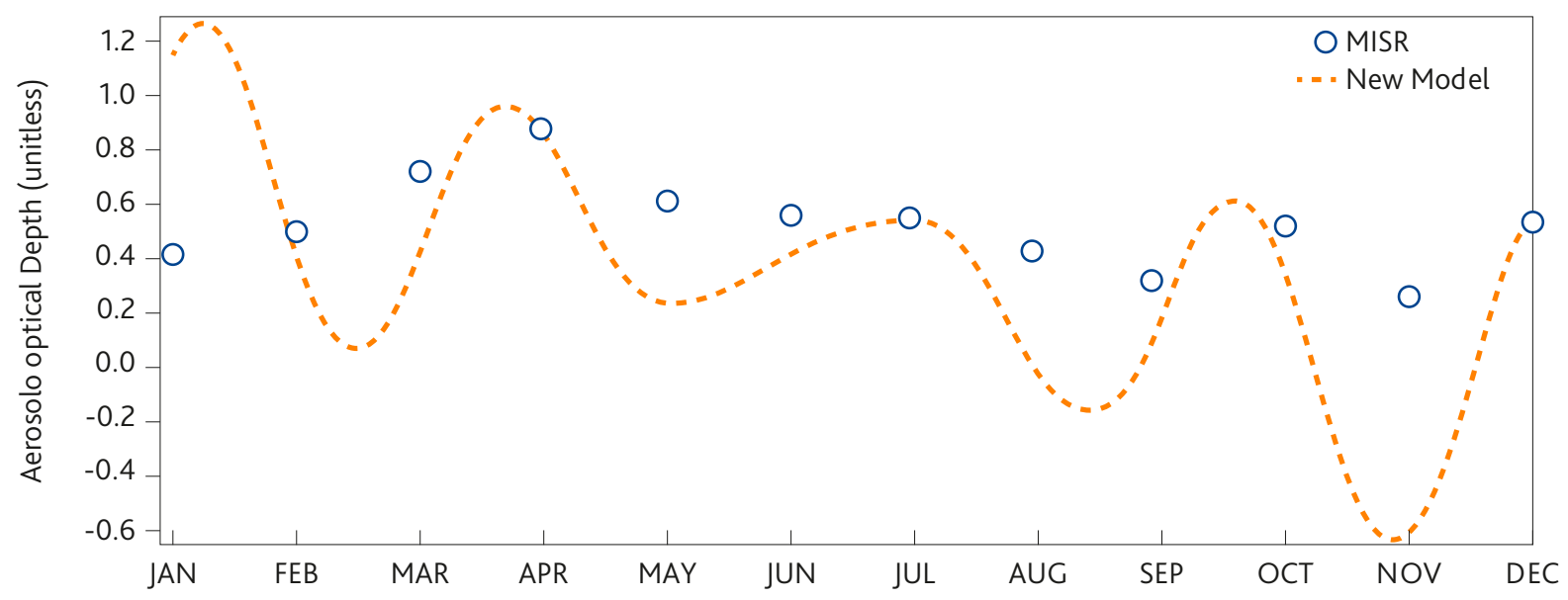

Figure 6. AOD for new model and MISR for the year 2004 


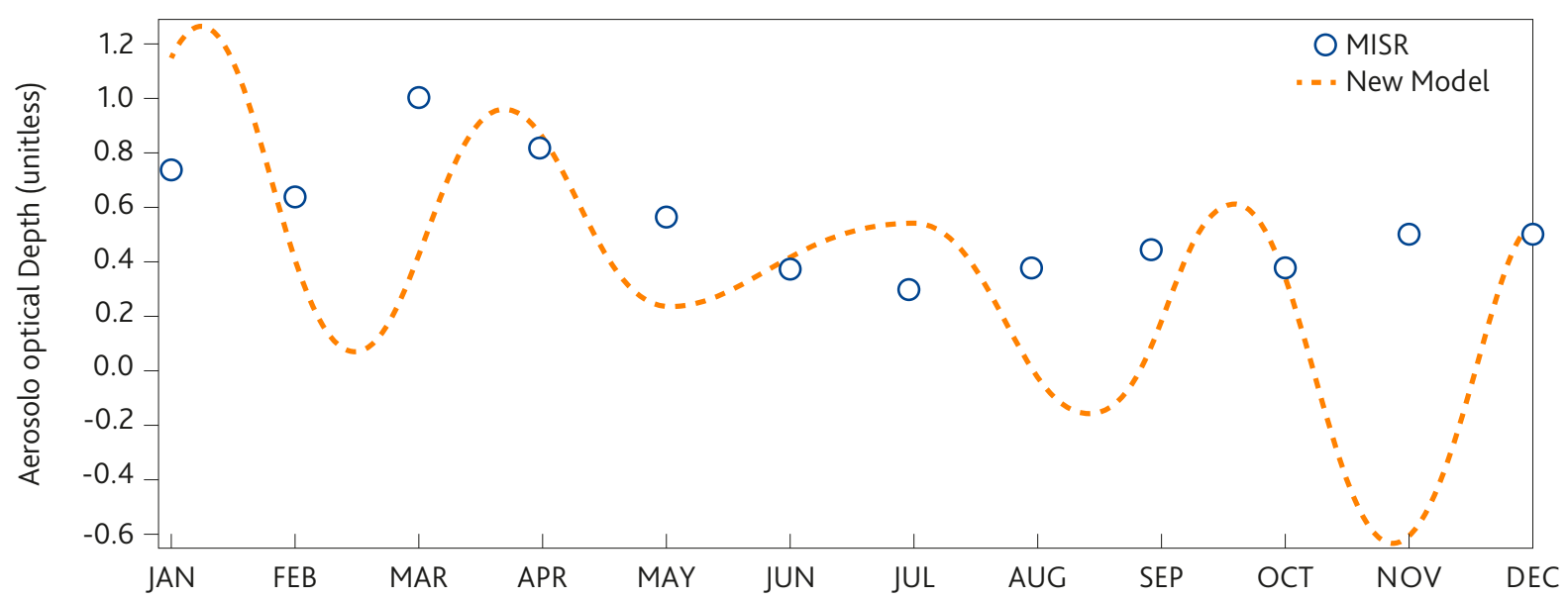

Figure 7. AOD for new model and MISR for the year 2007

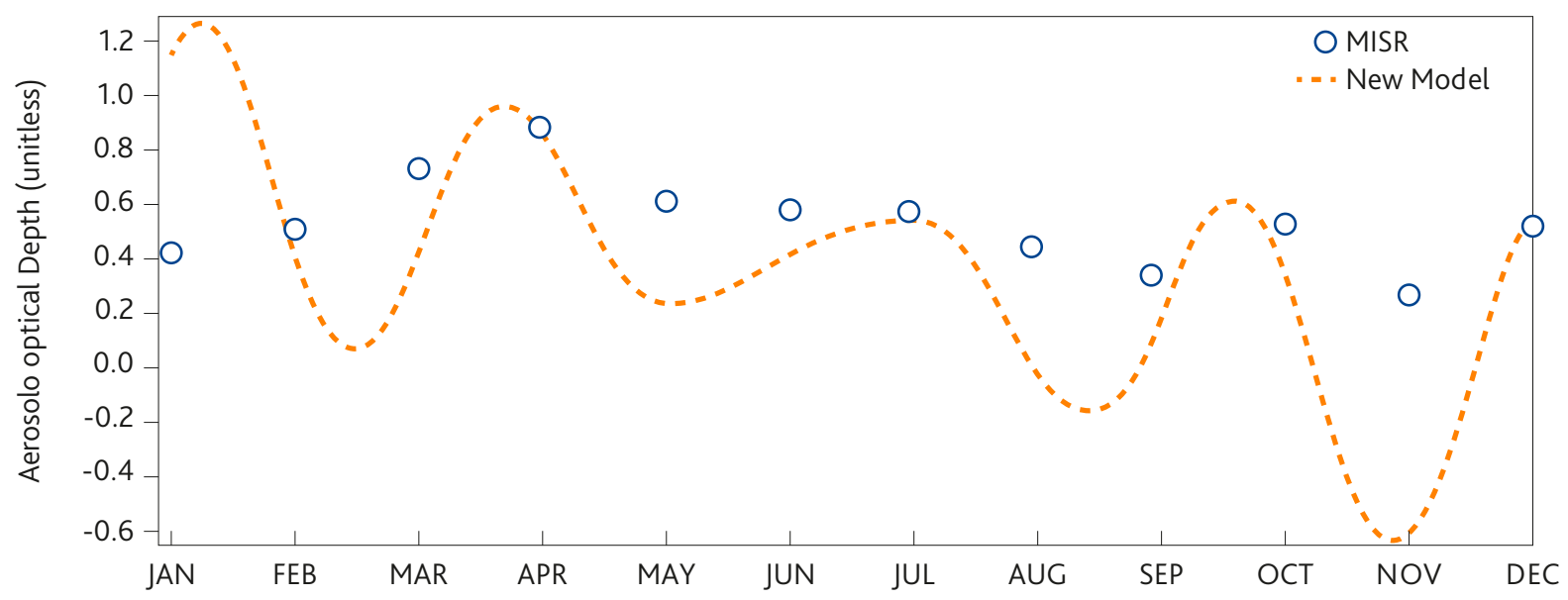

Figure 8. AOD for new model and MISR for the year 2011

Table 1. Atmospheric constants over Mubi

\begin{tabular}{|l|c|c|c|c|c|c|}
\hline Location & $a_{1}$ & $a_{2}$ & $n_{1}$ & $n_{2}$ & $\alpha$ & $\beta$ \\
\hline Mubi & 0.6085 & 0.6326 & 0.07197 & 0.1748 & $\pm \frac{\pi}{4}$ & $\pm \frac{\pi}{4}$ \\
\hline
\end{tabular}

sponding tuning constants should be 0.1748 . The recommended phase difference configuration for measuring devices used in Mubi is . It is important to note that this paper has significant interest to the International Telecommunication Union (ITU) model because it suggests an alteration in its known model shown as

$N=\frac{77.6 P}{T}+3.73 \cdot 10^{5} \frac{e}{T^{2}}=N_{d r y}+N_{w e t}(N-$ units $)$

Where $\mathrm{e}$ is the water vapour pressure (hPa), $P$ is the atmospheric pressure $(\mathrm{hPa})$, is the dry term of radio refractivity, is the wet term of radio refractivity and $T$ is the absolute temperature (K). The mathematical relationship between relative humidity and water vapour pressure is expressed in the following equation:
$e=\frac{R H}{100} a \exp \frac{b T}{T+c}$

(9)

Here $\mathrm{T}$ is the temperature in ${ }^{\circ} \mathrm{C}$ and the coefficients $\mathrm{a}, \mathrm{b}$ and $\mathrm{c}$ takes the following values: $\mathrm{a}=6.1121, \mathrm{~b}=$ 17.502 , and $c=240.97$. The implication of this research upon the understanding of the results from Leck and Svensson (2015) is that the determination of coefficients $\mathrm{a}, \mathrm{b}$ and $\mathrm{c}$ are influenced by the optical state over a geographical location. This study proposes an inclusion of the attenuation due to moving aerosols layer into the International Telecommunication Union (ITU) model which is significant via the atmospheric constants over Mubi. Upon this concept, we statistically examine the aerosol optical depth (AOD) distribution over Mubi per years as shown in Tables 2 and 3. 
Table 2. Statistical AOD analysis 2000-2006

\begin{tabular}{|l|c|c|c|c|c|c|c|}
\hline Statistical Tool & 2000 & 2001 & 2002 & 2003 & 2004 & 2005 & 2006 \\
\hline Mean & 0.35 & 0.38 & 0.5 & 0.4 & 0.47 & 0.49 & 0.45 \\
\hline $95 \%$ confidence interval & 0.12 & 0.12 & 0.12 & 0.11 & 0.08 & 0.12 & 0.11 \\
\hline $99 \%$ confidence interval & 0.17 & 0.16 & 0.17 & 0.15 & 0.12 & 0.18 & 0.16 \\
\hline Variance & 0.02 & 0.03 & 0.04 & 0.02 & 0.02 & 0.03 & 0.02 \\
\hline Standard deviation & 0.15 & 0.18 & 0.19 & 0.16 & 0.13 & 0.18 & 0.15 \\
\hline Coefficient of variation & 0.43 & 0.48 & 0.38 & 0.39 & 0.28 & 0.37 & 0.34 \\
\hline Skew & 1.64 & 0.44 & 0.76 & 0.43 & 0.07 & 0.97 & -0.33 \\
\hline Kurtosis & 2.72 & -1.25 & -0.8 & -0.8 & -1.54 & -0.17 & -0.83 \\
\hline Kolmogorov-Smirnov stat & 0.31 & 0.24 & 0.25 & 0.15 & 0.16 & 0.23 & 0.14 \\
\hline
\end{tabular}

Table 3. Statistical AOD analysis 2007-2013

\begin{tabular}{|l|c|c|c|c|c|c|c|}
\hline Statistical Tool & 2007 & 2008 & 2009 & 2010 & 2011 & 2012 & 2013 \\
\hline Mean & 0.41 & 0.4 & 0.4 & 0.39 & 0.48 & 0.39 & 0.37 \\
\hline $95 \%$ confidence interval & 0.12 & 0.09 & 0.08 & 0.11 & 0.14 & 0.12 & 0.09 \\
\hline $99 \%$ confidence interval & 0.18 & 0.13 & 0.12 & 0.16 & 0.2 & 0.18 & 0.13 \\
\hline Variance & 0.03 & 0.02 & 0.02 & 0.03 & 0.04 & 0.03 & 0.02 \\
\hline Standard deviation & 0.16 & 0.14 & 0.13 & 0.17 & 0.2 & 0.17 & 0.14 \\
\hline Coefficient of variation & 0.4 & 0.35 & 0.32 & 0.44 & 0.43 & 0.45 & 0.37 \\
\hline Skew & 1.12 & 0.5 & 0.29 & 1.03 & 0.69 & 0.32 & -0.07 \\
\hline Kurtosis & 0.17 & -1 & -0.69 & -0.47 & 0.22 & -0.96 & -1.12 \\
\hline Kolmogorov-Smirnov stat & 0.26 & 0.16 & 0.15 & 0.27 & 0.12 & 0.16 & 0.12 \\
\hline
\end{tabular}

The highest aerosol optical depth (AOD) mean, 95\% confidence interval, $99 \%$ confidence interval, variance, standard deviation and coefficient of variation was in 2005. The highest skew and kurtosis can be found in 2010. The highest Kolmogorov-Smirnov stat can be found in 2004. This results shows that the lower atmosphere of Mubi per years may not be dynamic as cities in the southern Nigeria (Emetere et al., 2015b). Hence we examine the atmospheric aerosol retention shown in Tables 4 and 5.

The year of highest atmospheric aerosols retention was found between 2004 and 2010. This shows that the skew and kurtosis may be good indicators of atmospheric aerosols retention. The significance of the atmospheric aerosols retention in a geographical region has great influence on aviation schedules (Gettelman, Chen, 2013), human health (Ronald, Lawrence, 1995), measuring instruments, energy budget and meteorology (Emetere, Akinyemi, 2013).

\section{Conclusion}

A stastistical examination of the aerosols loading over Mubi-Nigeria was observed and analytical dispersion model was used to estimate the aerosols loading for each month of the year. The atmospheric constants and tuning constants over Mubi were documented as 0.67 and 0.71 respectively. The atmospheric constants show that the volume of pollution in Mubi is enough to alter the ITU model. The highest aerosols retention over Mubi is $12.7 \%$. This shows that the self-cleansing mechanism of the atmosphere is gradually becoming weak to purge itself. Mubi monthly AOD trend agreed perfectly with the analytical dispersion model with an

Table 4. Atmospheric aerosols retention over Mubi 2001-2006

\begin{tabular}{|l|c|c|c|c|c|c|}
\hline Year & 2001 & 2002 & 2003 & 2004 & 2005 & 2006 \\
\hline Aerosol deposition & 1.22 & 7.53 & 0.026 & 12.67 & 5.56 & 1.22 \\
\hline
\end{tabular}

Table 5. Atmospheric aerosols retention over Mubi 2007-2013

\begin{tabular}{|l|c|c|c|c|c|c|c|}
\hline Year & 2007 & 2008 & 2009 & 2010 & 2011 & 2012 & 2013 \\
\hline Aerosol deposition & 2.25 & 1.38 & 1.1 & 7.46 & 0.09 & 0.21 & 4.13 \\
\hline
\end{tabular}


accuracy of $94.5 \%$. The aerosols gamma distribution over Mubi is maximum in March and April. Hence, the type of aerosols in Mubi is majorly dust particulates emanating from the northeast wind. The year of highest atmospheric aerosols retention was found between 2004 and 2010. The highest aerosol optical depth of 0.86 occurred in 2002, 2005 and 2011 . The lowest aerosol optical depth of 0.14 occurred in 2001 and 2013. The average AOD over Mubi is given as 0.44. The significance of the atmospheric aerosols retention in a geographical region has great influence on aviation schedules, human health, measuring instruments, energy budget and meteorology.

\section{Acknowledgement}

The authors appreciate NASA for using their satellite dataset. The author expresses gratitude to Covenant University for the partial sponsorship.

\section{References}

Accuweather 2015. Assessed at: http://www.accuweather.com/en/ng/Mubi/253466/weather-forecast/253466 (Retrieved 23rd June, 2015).

Anuforom, A.C. 2007. Spatial Distribution and Temporal Variability of Harmattan Dust Haze in Sub - Sahel West African Atmosphere. Environ. 41, 79-90.

Bryce, J. Boschi-Pinto, C., Schiobuya, K. Black, R.E. 2005.The WHO Estimate of the cause of Death in Children. Lancet 365, 1147-1152.

Emetere M.E., Akinyemi M.L., Akinojo O. 2015a. Parametric retrieval model for estimating aerosol size distribution via the AERONET, LAGOS station. Environmental Pollution 207 (C), 381-390.

Emetere, M.E., Akinyemi M.L., Akin-Ojo O. 2015b. Aerosol Optical Depth Trends over Different Regions of Nigeria: Thirteen years Analysis. Modern Applied Science 9,9, 267-279.

Emetere, M.E., Akinyemi, M.L 2013. Modeling Of Generic Air Pollution Dispersion Analysis From Cement Factory. Analele Universitatii din Oradea-Seria Geografie 231123,628, 181-189.

Gettelman, A., Chen, C. 2013. The climate impact of aviation aerosols. Geophysical Research Letters 40, 1-5.

Kommalapati, Raghava R., Valsaraj, Kalliat T. 2009. Atmospheric aerosols: Characterization, chemistry, modeling, and climate 1005. Washington, DC: American Chemical Society. pp. 1-10. doi:10.1021/ bk-2009-1005.choo1. ISBN 9780841224827. Retrieved 10 July 2014.

Leck, C. Svensson, E. 2015. Importance of aerosol composition and mixing state for cloud droplet activation over the Arctic pack ice in summer. Atmos. Chem. Phys. 15, 2545-2568.

McTainsh, G.H., NickLing, W.G., Lynch, A.W. 1997. Dust Deposition and Particle Size in Mali West Africa. Catena 29, 307-322.

Morris, S.S., Black, R.E. Tomaskoric, L. 2003. Predicting the Distribution of Under-Five Deaths by cause in Countries Without Adequate Vital Registration System. J. Epidemol 32, 1041-1051.

Mubi, A.A., Muhammad, I.R., Michika, S.A., Midau, A. 2011. Threaten Health Challenges of Trade Animals in International Livestock Market, Mubi, Nigeria. Global Veterinaria 7, 6, 596-6oo.

Rutherford, S., Clark, E., McTainsh, G., Simpson, R., Mitchell, C. 1999. Characteristics of Rural Severity in Brisbane Australia. Int. J. Biometeoral 42, 17-25.

Ronald E. Wyzga, Lawrence J. Folinsbee 1995. Health effects of acid aerosols, Water, Air, and Soil Pollution, 85,1, 177-188.

Stahlmecke, S. Wagener, C., Asbach, H. Kaminski, H., Fissan, T.A.J., Kuhlbusch 2009. Investigation of airborne nanopowder agglomerate stability in an orifice under various differential pressure conditions. Journal of Nanoparticle Research 1625-1635.

Sunnu, A., Afeti, G., Resh, F.A. 2008. A long Term Experimental Study of the Saharan Dust Presence in West Africa. Atmos. Res. 87,13-26.

SITREP 2014. Assessed at: https://www.humanitarianresponse.info/.../SITREP\%20\%20Adamawa\%2 (19 ${ }^{\text {th }}$ March, 2016)

Uduma, A.U, Jimoh W.L.O 2013. High Incidence of Asthma, Bronchitis, Pneumonia and Sinusitis in Mubi State, North West Nigeria during Saharan Dust Events. American Journal of Environment, Energy and Power Research 18, 174-185.

Weisstein, E. 2004. Kurtosis. In MathWorld-A Wolfram Web Resource. Wolfram Research, Inc. Champaign, IL. http://mathworld.wolfram.com/Kurtosis. html. (Accessed on 19 ${ }^{\text {th }}$ March, 2016)

Weisstein, E. 2005. Skewness. In MathWorld-A Wolfram Web Resource. Wolfram Research, Inc. Champaign, IL. http://mathworld.wolfram.com/Skewness.html. (Accessed on $19^{\text {th }}$ March, 2016)

Wiki 2016. http://wiki.landscapetoolbox.org/doku. php/remote_sensor_types:misr (Accessed on $19^{\text {th }}$ March, 2016) 